\title{
Factors Affecting the Length of Tourist Stay Time in the Case of South Omo Zone, Ethiopia
}

\author{
Mr. Israel Bereket \\ Lecturer, Department of Economics, Jinka University, Jinka Ethiopia
}

\begin{abstract}
Tourism is a fast-growing global industry, contributing huge economic benefits to the worldwide community. Ethiopia is well known country by tourism potential. Among the tourist attraction sites South Omo Zone is a major tourist destination with enormous tourism potential. The main objective of this research is to identify the factors affecting the length of tourist stay time in the zone. Turmi, Keyafer and Jinka towns are selected purposively from the zone due to high tourist potential area and the data was collected using observation, key informant in-depth interview, and self-administered tourist questionnaire surveys. The data analysed by using appropriate software that is SPSS. The finding revealed that among the variables listed the chi-square result shows that the association between length of tourist staying time with purpose of visit, level of road infrastructure, facilities and services at destinations, personal safety and security, guide knowledge and level of attractiveness are significant and strong. The remained variable such as age, gender of the respondent, education level of the respondents, occupation, marital status, and means of transportation, tourist information, average daily expense and entrance fee has not significant effect on the length of tourist staying time in the destination areas. Therefore in order to lengthen the staying time of tourist road infrastructure, and service \& facilities around the destination must be improved by the concerned body. Also the government should attempt to make the safety and security to the highest level in order to make the tourist in the destination feel the best and the most enjoyable although for protecting of the tourist from risk and from any possible litigation. Giving training for local guides to be ethical, skillful, trustworthy, disciplined and knowledgeable also unquestionable.
\end{abstract}

Keywords: Staying Time, Tourism, and South Omo Zone.

DOI: $10.7176 / \mathrm{JTHS} / 51-01$

Publication date:October $31^{\text {st }} 2020$

\section{INTRODUCTION}

\subsection{BACKGROUND OF THE STUDY}

Tourism is a fast-growing global industry, contributing huge economic benefits to the worldwide community. Tourism attractions, sites and destinations have been drawing visitors from different countries for centuries. According to the United Nation World Tourism Organization (2015), there are a growing number of tourism destinations throughout the world which have created opportunity for investment in tourism, changing it into a key driver of socio-economic progress through the creation of jobs and enterprises, export revenues, and infrastructural development.

As a land of multiple tourist attractions and a visitor friendly people which is conscious of its historical heritage, Ethiopia is truly a country of great tourism potential. It was this recognition of a great potential that encouraged Ethiopia in the 1960's to start a tourism industry. After an initial period of rapid growth, the industry underwent a fast decline and virtual stagnation for many years due to the revolution that brought the military to power in 1974, the consequent turmoil, and recurrent drought and famines. The arrival of a new government in 1991 brought the first change, with greater emphasis on a free-market economy, improving infrastructure and the construction of new roads, highways and airports. The tourism industry in Ethiopia could be legitimately described as one that is still in its infancy. Our present government considers tourism to be an industry with great potential for our country (Yimer, 2016).

According to (SNNPRS) Culture and Tourism Bureau, the Region is endowed with diverse natural, cultural, and historical resources. South Omo Zone is known for its cultural tourism resources. Though the tourist flow trend didn't grow linearly as desired, it shows a $16.7 \%$ average annual growth for the last 11 years. Large number of tourist visited the zone in the years 2007/08, 2011/12 and 2014/15. Domestic tourist flow to the zone had never been beyond international tourists flow before 2011/12, however, domestic tourist increased due to mega projects under taking on the region; Kuraz sugar factories project and road construction that have mobilized huge number of people from different parts of the country have been larger than international since 2011/12 (Ermias \& Azmach, 2017).

\subsection{STATMENT OF THE PROBLEM}

Internationally and locally, tourism represents an important source of foreign exchange earnings; indeed, it has been suggested that the potential contribution to the national balance of payments is the principal reason why governments support tourism development. For many developing countries, tourism has become one of the 
principal sources of foreign exchange earnings whilst even in developed countries the earnings from international tourism may make a significant contribution to the balance of payments in general, and the travel account in particular (Yabibal, 2010).

Previously there are several studies were conducted on tourism and hospitality industries across the world. In Ethiopia also several theoretical and empirical research were studied in different time across different region, and areas as well as at county level however most of the studies were focused on national tourism policy and its performance; the specific tribes cultural, economic and social life style; also on determinate of tourist satisfaction; on anthropological, and archaeological issues; community based tourism, challenge and prospect of tourism, about tourism potential, and so on (for instance Shaw, 1994; Yabibal, 2010; Agumas, 2010; Ambelu, 2011; Alemayehu, 2011; Tadesse, 2015; Tekabe, 2016; Yimer, 2016 and Ermias \& Azmach, 2017).

Therefore the above previous studies, don't consider the factors affecting the length of Tourist staying time so that the current researcher found it worthy to assess the impact of the demographic, economical, and other service and facilities related factors on the length of tourist staying time in South Omo Zone which is not considered in the previous studies. This study emphasised on the selected major tourist destination of the zone.

\subsection{OBJECTIVE OF THE STUDY General Objective}

$>$ The general objective of the study to identify the factors affecting the length of tourist stays time in South Omo Zone.

\section{Specific Objectives}

* To assess the demographical factors affecting tourist stay time in South Omo Zone,

* To explore the impact of level infrastructure and facilities on the length of tourist stay time in the study area,

* To assess the impact of purpose of visit on length of tourist staying time in South Omo Zone,

* To identifies the relationship between safety and security issue with length of tourist satay time in the study area.

* To assess the impact of level of attractiveness on length of tourist staying time in SOZ.

\subsection{RESEARCH QUESTIONS}

$>$ What are the demographic factors affecting the tourist staying time in South Omo Zone?

$>$ What is the impact of level of infrastructure and facilities on tourist staying time?

$>$ What is the impact of Purpose of visit on the length of tourist staying time in SOZ?

$>$ What is the relationship $\mathrm{b} / \mathrm{n}$ safety and security issues with length of tourist staying time?

$>$ What is the impact of level of attractiveness on the length of tourist staying time in SOZ?

\section{RESEARCH METHDOLOGY}

\subsection{Research Design and Data Collection Methods}

In order to address the stated objectives the study used cross-sectional data to investigate the factors affecting the length of tourist stay time in the zone. This research was tried to use quantitative research methods to make more valid \& reliable. The primary data were collected through tourist questionnaires surveys, interviews, focus group discussion and observation to achieve the objectives and answer the research questions posed.

\subsection{Sampling Procedure and Method of Data Analysis}

This paper was planned to achieve the objective by using purposive sampling techniques. First the study used purposive sampling techniques to select Jinka, Turmi, and Keyafer town from South Omo Zone, since of the towns are known by high tourist potential and they comprise around $95 \%$ of the total tourist's arrival in the zone. In order to determining an appropriate sample size the researchers depends on the factors such as availability of time, cost, human resources and the nature of the population from which sample is drawn. Therefore considering the above factors the researchers selected 150 respondents purposively. The data entered and analysed by using appropriate software that is SPSS. Descriptive statistical analysis would be used for the comparisons of the respondents in different parameter. In addition frequencies, tables, and Chi-square distribution used to display results of findings.

\section{Result and Discussion}

The socio-economic and demographic characteristic of the surveyed respondents summarized as follow to shows whether there is strong and significant associations with the length of tourist staying time the following discrete variables are included in the below table. 
Table 1.1 Summary of Descriptive Statistics for Discrete Variable by Length of Tourist Stay Time in the Destinations

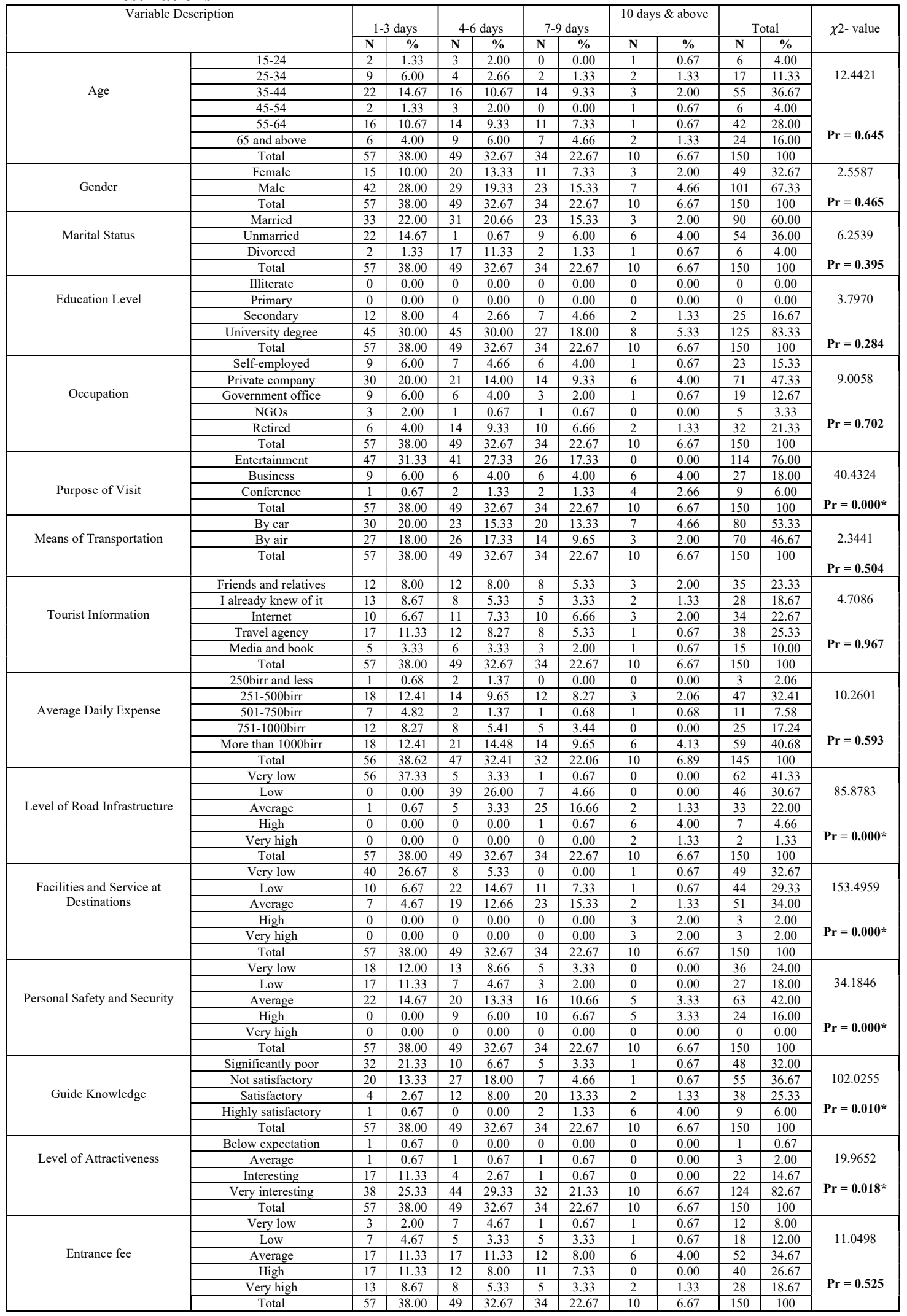


The finding in the above table revealed that among the variables listed the chi-square result shows that the association between length of tourist staying time with purpose of visit, level of road infrastructure, facilities and services at destinations, personal safety and security, guide knowledge and level of attractiveness are significant and strong. The remained variable such as age, gender of the respondent, education level of the respondents, occupation, marital status, and means of transportation, tourist information, average daily expense and entrance fee has not significant effect on the length of tourist staying time in the destination areas.

In regard to purpose of visit as shown from the above table the chi-square result is $(\chi 2) 40.4324$ with $\mathrm{P}=$ 0.000 this shows that purpose of visit is significant at $1 \%$ so that there is strong association with the length of tourist stay time. The other factor determine their stay time is road infrastructure moreover level of road infrastructure has strong and significant association with length of tourist staying time and the chi-square result is 85.8783 with $\mathrm{P}=0.000$ i.e also this variable is significant at $1 \%$. Moreover those respondents who are stay short period (1-3days) rate the level of the road infrastructure as very low (above $37 \%$ of respondents). Therefore attentions must be given for improving the level of road infrastructure in order to increase the staying period of tourists in the destination beside that maintenance and follow up is needed for road infrastructure which serves long time.

In addition to this facilities and service which are hotels service, internet, water, electricity, food and so on have significant impact on the length of tourist stay since good facilities and service has positive impact on the level of satisfaction also the chi-square results from the above table shows as 153.4959 with $\mathrm{P}=0.000$ that means this variable affect the length of time at $1 \%$ significance level although among the sampled respondent who stayed short time rate the overall facilities as very low and low. Therefore improving overall tourist facilities and services at destination is unquestionable. Personal safety and security also has strong association with the length of tourist staying time and the chi-square result for this variable is 34.1846 with $\mathrm{P}=0.000$ and significant at $1 \%$ level.

Finally, guide knowledge $\&$ discipline also has significant association with the tourist stay time, $\chi 2$ result is $\mathrm{P}=0.010$ and those tourists who are rate the performance of the tour guide interims of knowledge $\&$ discipline as significantly poor \& not satisfactory stayed short period. Promoting the capacity of local guide's is important to increase their number of night staying in the destination. Therefore in order to accelerate the performance of the sector the above significant factor must be addressed by the concerned body.

\section{CONCLUSION AND RECOMENDATION}

As a land of multiple tourist attractions and a visitor friendly people which is conscious of its historical heritage, Ethiopia is truly a country of great tourism potential. Like other regions, the SNNPRS region is well endowed with diverse natural, cultural, and historical resources. The Region is well known for its abundant actual and potential tourist destinations in the country and it is unique in taking up the highest diversity of nations, nationalities, and peoples. From the region tourism attraction South Omo Zone is known for its cultural tourism resources. Even if the zone is known by potential tourist destination the tourism industry in the zone is still in infancy. This study was conducted on the factors affecting the length of tourist staying time in the south omo zone. To address the research objective, the study used primary data collected from 150 sampled tourists.

Finally the study revealed that purpose of visit has a strong association with the length of tourist stay time with chi-square result is $(\chi 2) 40.4324$ with $\mathrm{P}=0.000$, and significant at $1 \%$. Level of road infrastructure, has strong and significant association with length of tourist staying time and the chi-square result is 85.8783 with $\mathrm{P}=0.000$ i.e also this variable is significant at $1 \%$. Also facilities $\&$ services, and safety and security variable has strong relationship with length of tourist stay time and the chi-square result is $(\chi 2) 153.4959$ with $\mathrm{P}=0.000 ; 34.1846$ with $\mathrm{P}=0.000$ respectively. Moreover tour guide's knowledge and disciplines; and level of attractiveness have also strong and significant association with the length of tourist staying time. The remained age, sex of the respondent education level of the respondents, occupation, marital status, and means of transportation, tourist information, average daily expense and entrance fee has not significant effect on the length of tourist staying time in the destination areas.

Having the above conclusion the researcher recommended the following things; as the study revealed that level of road infrastructure has a key association with length of tourist stay so that the concerned body must take action to improve the provision and quality of the road infrastructure as well. The next important things is facilities and services needs to much improvement in the provision of good electricity power, better internet connectivity, clean water sanitation and the like in order to increase the length of tourist stay in the zone. Also the government must protect the safety and security of tourists to lengthen the tourist staying time as well as giving capacity building training for tour guide is important in order to scale up their performance.

\section{REFERENCE}

Agumas, F. (2012). The Impact of Tourism on Culture on Tourist Destination Area: A Case Study of Hamer People, Addis ababa University, Addis Ababa, Ethiopia.

Alemayehu, D. (2011). Challenge and Opportunities for the establishment of community based Ecotourism in the 
Awash National Park Area, Unpublished Thesis, Addis Ababa University.

Ambelu, G. (2011). Practices, Challenges and Opportunities of Community Based Ecotourism Development in Meket Woreda North Wollo; Unpublished Thesis, Addis Ababa University.

Ermias, K., \& Azmach, T. (2017). Tourism potential and constraints: considering the natural and cultural attractions of South Omo, Ethiopia. African Journal of Hospitality, Tourism and Leisure , 6 (1), Hawassa University Ethiopia.

Shaw, G. (1994). Critical Issues in Tourism, a Geographical Perspective, T. J. Press Ltd. Great Britan.

SNNPRS Report, The Region Parks, Culture and Tourism .

Tadesse, K. M. (2015). Ethiopia:Opportunities and Challenges of Tourism Development in the Addis Ababa-upper Rift Valley corridor. USA .

Tekabe, S. S. (2016). Challenges and Prospectus of Ethiopian Tourism Industry. International Journal of Scientific and Research Publications , 6 (6).

UNWTO. (2015). Tourism Highlight. Madrid, spain.

Yabibal, M. W. (2010). Tourist Flows and its Determinants in Ethiopia. Ethiopian Development Research Institute, Addis Ababa, Ethiopia.

Yimer, A. (2016). Challenge and Prospect of Ethiopian Tourism Policy. Global Journal of Management and Business Research: Real Estate, Event \& Tourism Management . 